\title{
Article
}

\section{Preventing Road Accidents with AESLEME's 'It Can Happen to You' programme. Assessment of increased knowledge one month after a presentation}

\author{
Mar Cogollos-Paja ${ }^{1}$, Juan Angel García-Reneses ${ }^{2}$ and Rafael Herruzo-Cabrera 3,* \\ 1 Psychologist, President of AESLEME \\ 2 Physician specialized in Rehabilitation, Vice-President of AESLEME \\ 3 Professor of Preventive Medicine and Public Health, Universidad Autónoma de Madrid \\ * Contact: Rafael.herruzo@uam.es; Tel.: +34-914975432
}

\begin{abstract}
Introduction: Road traffic accidents are a real pandemic and incur expenses amounting to 1-2\% of every country's GDP. AESLEME (Association for the Study of Spinal Cord Injuries) - devoted to teaching road safety and health to prevent road accidents - has celebrated its 30th anniversary. AESLEME's instructors are health workers and people with spinal cord injuries caused by road accidents: their presentations - teaching road safety and sharing information on irreversible injuries - are enhanced by personal stories that help schoolchildren to acquire knowledge on this matter. However, until now, we had not assessed how far this acquisition of knowledge had reached. Methods used: Two multiple-choice tests were given to each of the 8,106 students (12-14 years) who took part. Of the four possible answers, only one of them was correct. The first multiplechoice test was taken before the presentation and the second was taken one month later. Results: After assessing the answers, there was a change in the tendency of the number of correct answers before/after answers for the multiple-choice test, and the number of correct one's rose one month after the presentation. This increase is statistically significant $(\mathrm{p}<0.01)$ and represents a national increase of $61 \%$ in the number of correct answers, although this varies from $8 \%$ to $278 \%$ depending on the region. Conclusions: The assessment, involving over 8,000 people, showed that there has been an improvement in road safety knowledge thanks to education provided by AESLEME's instructors, and a statistically significant increase was obtained throughout Spain, with an average of $61 \%$ (confidence level 95: 53\% and 64\%).
\end{abstract}

Keywords: prevention; road-traffic-accidents; education-health; schoolchildren; change-attitude

\section{Introduction}

Road traffic accidents are a real pandemic and because they have been present in our societies for years, end up being given little attention as they are in the news every day.

However, all over the world they produce huge numbers of deaths, great suffering, the need for medical attention, not to mention economic loss, which should be considered to reduce - to the greatest extent possible - this drain of lives and the resources of every country.

The numbers are so great ${ }^{1-7}$ that we have become indifferent to them and they do not trigger a reaction in us. We must therefore take another look at this matter and imagine and visualize all the losses involved in it:

- More than 1.3 million people die each year worldwide (similar to the number of deaths from coronavirus in the first 10 months of 2020), and between 20 and 50 million people are seriously injured. Road accidents are the leading cause of death among children and young people aged between 5 and 29.

- In the 27 member states of the European Union, about 23,000 people (51 deaths per million inhabitants) are killed and 1.5 million are injured. 
- Spain is the sixth safest country in the EU with a mortality rate of 36 deaths per million inhabitants (just over 1,000 deaths per year) and over 130,000 injuries each year, of which almost 10,000 require hospitalization. Around 30 years ago, we were among the countries with the highest road accident rate in Europe $(>9,000$ deaths in 1989, the highest since records began, even though there are twice as many vehicles on our roads today). Lethality (deaths/victims of road accidents) has also dropped and is around 1\%, meaning it has decreased by three quarters in two decades. A problem emerges, however, if we look at different sources; although the number of fatalities is similar, the numbers of injured can be much higher than the 'official' ones (double for serious injuries and four times as high for minor ones). Expenditure, both direct (caring for victims) and indirect (loss of earnings), makes up between $1 \%$ and $2 \%$ of GDP each year. That is why it is vital to continue making the effort to prevent these accidents.

Prevention measures 8,9 also exist, but are not always implemented or followed: road improvement and signage, compliance with traffic regulations, and a system of fines in the event of infringements, in particular speeding, consumption of substances which reduce a driver's ability (alcohol and other drugs), use of restraint systems and helmets for two-wheeled vehicles, improved vehicle design to make them safer for their occupants, etc. But often the key is road safety education offered at school to establish healthy habits when it comes to mobility. This is very difficult to do as good habits can be disregarded because of laziness, bad examples being set, etc. In addition, creating preventive measures can lead to more work and more time being spent, and not everyone is willing to make the effort. That is why road safety awareness campaigns to relearn and maintain good habits to prevent road traffic accidents are so important ${ }^{10}$.

AESLEME (Association for the Study of Spinal Cord Injuries) is a non-profit NGO declared to contribute to the public good and accredited as a transparent NGO that follows ISO 39001 guidance on road safety and 9001 for quality - that has, for 30 years, dedicated itself to providing education on road safety and health to prevent road accidents. The Association's activities also focus on psychological support for victims. In fact, most of AESLEME's members have suffered a road accident, the consequences of which changed their lives - in a fraction of a second - forever. They are, therefore, very suitable instructors for disseminating prevention campaigns in places such as schools, universities, the armed forces and companies: they not only talk about risks, prevention measures, etc. but also link this knowledge with their own life stories (the physical, psychological and social problems they face in their day-to-day lives, etc.). This captures the attention of audiences much more and becomes a powerful stimulus for them to modify their behaviour and adopt healthy habits when it comes to sharing the roads in a responsible way and contributing to safe mobility.

With slogans like 'A Second Can Change your Life', 'It Can Happen to You', etc., AESLEME's professionals have disseminated road safety campaigns in over 48,000 places of learning, in particular schools and high schools. They have also carried out campaigns aimed at youngsters, such as 'If You Control, You'll Return' and 'Hold on to Life'; 'Defend Yourself', for people in the armed forces; 'Move About Safely and Protect Them', for the elderly and for companies, etc. In the 30 years since it was founded, AESLEME and its activities have reached over 4 million people.

These campaigns were designed, of course, with full belief in their effectiveness and aimed to fulfil their intended purpose, but an objective view has also been sought. A decision was therefore taken to conduct a study with a large sample of schoolchildren, giving them a very simple survey to take one month after a presentation to assess the increase in their knowledge about road safety.

\section{Materials and Methods}

Among AESLEME's instructors are healthcare workers and people with spinal cord injuries caused by road accidents; their presentations are interesting and are adapted to 
schoolchildren of different ages. The main strong point of each presentation is interaction with the audience, explaining not only the epidemiology of road accidents, the risks, and possible irreversible injuries that the instructors suffered (paraplegia or quadriplegia) but also experiences about their new reality. These are testimonies with which schoolchildren empathise and that motivate them to learn about what they have heard ${ }^{11,12}$.

To assess the schoolchildren's knowledge acquisition of the basic concepts for the prevention of these kinds of accidents, AESLEME collaborated with several schools and high schools by giving presentations there. Prior permission, signed by the schools and by the parents, had to be drawn up and agreed upon. This quasi-experimental study (pre/post-presentation) conducted with a convenience sample was based on accessibility to the population and willingness to participate in our investigation.

Two multiple-choice tests were given to each student; of the four possible answers, only one was considered correct.

They took the first multiple-choice test before the presentation, and the second one a month later. Both questionnaires, lasting 10 minutes each, were answered in the classroom.

The multiple-choice test is shown in the appendix and includes all the information the students were asked to give (age, gender, school or high school, their year, city, region, and year).

The answers were rated as correct or incorrect and entered into a database to compare the before/after answers in each region and in the country. It was thus possible to determine how many students did not answer any question correctly before the presentation, and how many answered in the same way a month after the presentation. The same comparison was made with the correct answers for all 12 questions - 12 being the maximum possible score - both before and after the educational presentation on traffic accident prevention.

Since the answers to both questionnaires were anonymous, we decided to compare the percentages of correct answers to the 12 questions asked both times, exploring the significant increase in these percentages by means of odds ratios. The purpose of this study was to describe the intervention, and provide some descriptive values based on the results obtained before and after the presentation, but we were also able to assess the statistical significance associated to the intervention based on the percentages of children who answered the questionnaire correctly on both occasions.

The statistical study was carried out using the StatCalc programme (Epi Info, CDC), which calculated the stratified results by the study's variables, their respective chi-squared values and the odds-ratios (OR) which calculated the $2 \times 2$ tables obtained for Spain and several regions, their statistical significance and the odds ratio (OR) with their respective $95 \%$ confidence limits.

\section{Results}

Table I shows the percentages of students who answered correctly, before and after the presentation, stratified (in rows) by the number of correct answers $(1,2,3$, etc. or 12 , which was the highest score), and, as can be seen, $5 \%$ of students answered all of them correctly, even before the start of the presentation. Each column indicates where the surveys were conducted, and groups them by region or for Spain as a whole.

This study only presents the results of 8,106 students aged between 12 and 14 years of age (Year 6 of Primary School, or Year 1 and 2 of Secondary School) i.e., 8,106 multiplechoice tests taken both before and after the presentation. The number of students varies by region depending on different reasons, for example: Andalusia, 776 students; Aragon, 435; the Canary Islands, 2,520; Castilla La Mancha, 198; Extremadura, 670, according to the time the speakers had, as well as the possibilities and willingness of the schools to 
conduct these surveys. The results do not vary significantly with regard to age and sex, so they have been presented together, without stratifying these factors.

As can be seen in Table I and Figure 1, there is an inverse direction in the before/after percentages as the high number of correct answers (e.g., 9 or more) increased after the presentation. This was expected as our initial premise was about conveying knowledge (in addition to transmitting emotion), and this knowledge was linked to the number of correct answers.

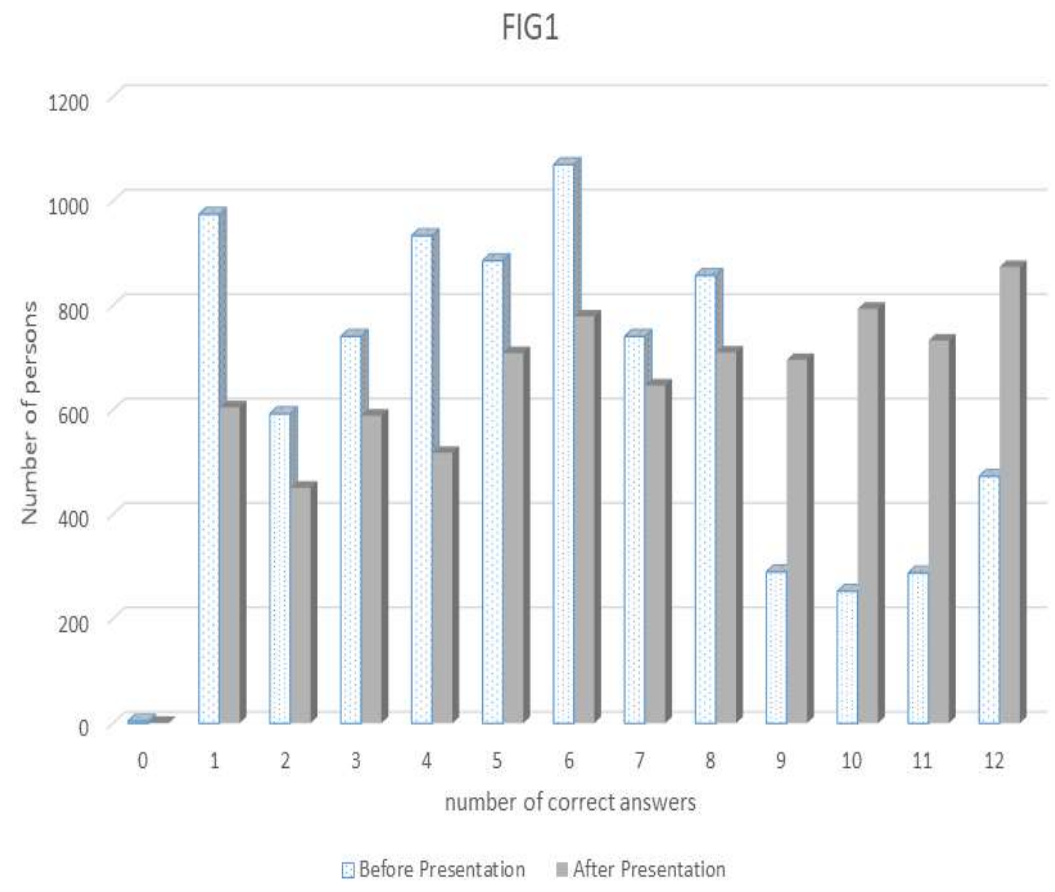

Figure 1. Global data for Spain with correct answers to the survey before and after the presentation.

The set of correct answers was calculated by region and for Spain as a whole. So, if 593 students each answered two questions correctly, we would have 1,186 correct answers; or, if 473 students answered 12 questions correctly, we would have 5,676 correct answers, etc. The total number of possible correct answers would be the product of the number of students by the number of questions (12). By knowing how many correct answers there were in one place, the number of incorrect answers - both before and after the presentation - can be assessed; this data can be used to draw up dichotomous tables with which the increase of knowledge can be calculated, both in Spain as well as in some specific regions by means of their odds ratio and their statistical significance.

Table II shows the global and regional data obtained for Spain, the statistical significance, and the increase in correct answers after the presentation. As can be seen, this increase is statistically significant ( $\mathrm{p}<0.01$ or more) and this means, globally, a $61 \%$ increase in correct answers after the presentation was given by the AESLEME speaker. The same thing was done in some regions: the increase in correct answers went from only $8 \%$, while others had very high scores, such as over $200 \%$ (double the number of correct answers after the presentation), all of which is a significant increase. 
Table I: Distribution of percentages of students according to the number of correct answers (before/after), and globally in Spain versus the different regions.

$$
\% \text { of students }
$$

\begin{tabular}{lllllllll} 
& \multicolumn{2}{r}{ Spain } & \multicolumn{3}{c}{ Aragon } & \multicolumn{2}{c}{ Andalusia } & \multicolumn{2}{c}{ Canary Islands } \\
No. answ & B & A & B & A & B & A & B & A \\
$0-1$ & 12.02 & 7.46 & 1.38 & 0 & 0.13 & 0.13 & 8.41 & 10.32 \\
2 & 7.31 & 5.56 & 0.23 & 0 & 1.29 & 0.26 & 4.68 & 6.27 \\
3 & 9.14 & 7.27 & 4.14 & 0 & 5.03 & 1.29 & 8.49 & 9.76 \\
4 & 11.52 & 6.39 & 9.43 & 0 & 11.34 & 1.03 & 15.71 & 8.17 \\
5 & 10.93 & 8.75 & 16.32 & 5.05 & 16.49 & 2.06 & 9.92 & 10.48 \\
6 & 13.2 & 9.61 & 27.13 & 6.43 & 20.75 & 3.48 & 10.08 & 10.71 \\
7 & 8.14 & 7.98 & 17.93 & 13.79 & 19.72 & 8.12 & 9.92 & 7.7 \\
8 & 10.58 & 8.76 & 15.4 & 17 & 13.14 & 8.89 & 14.52 & 6.75 \\
9 & 3.58 & 8.58 & 4.83 & 17 & 7.86 & 13.79 & 1.03 & 4.92 \\
10 & 3.12 & 9.79 & 0.92 & 9.9 & 4.25 & 16.62 & 3.02 & 6.9 \\
11 & 3.55 & 9.04 & 0.92 & 8.4 & 0 & 23.71 & 5.32 & 7.94 \\
12 & 5.43 & 10.78 & 0.46 & 8.04 & 0 & 20.62 & 8.89 & 10.08
\end{tabular}

Abbreviations: answ = answers; $\mathrm{B}=$ Before, $\mathrm{A}=$ After

Table I (cont.): Distribution of percentages of students according to the number of correct answers (before/after), and globally in Spain versus the different regions.

$$
\% \text { of students }
$$

\begin{tabular}{lllllllll} 
& \multicolumn{2}{r}{ Spain } & \multicolumn{3}{c}{ CM-Mad } & \multicolumn{2}{c}{ Extremad } & \multicolumn{2}{c}{ Basque C. } \\
No. answ & B & A & B & A & B & A & B & A \\
$0-1$ & 12.02 & 7.46 & 2 & 0 & 0 & 0 & 21.4 & 9.75 \\
2 & 7.31 & 5.56 & 3 & 0 & 0.3 & 0.9 & 13 & 7.96 \\
3 & 9.14 & 7.27 & 5.1 & 0 & 0.6 & 0.6 & 13 & 8.3 \\
4 & 11.52 & 6.39 & 2 & 0 & 8.06 & 0.6 & 10.31 & 8.9 \\
5 & 10.93 & 8.75 & 6 & 0 & 14.93 & 3.88 & 9.27 & 10.69 \\
6 & 13.2 & 9.61 & 23.7 & 0 & 20.3 & 5.37 & 10.1 & 11.36 \\
7 & 8.14 & 7.98 & 12.1 & 1.59 & 25.07 & 8.06 & 1.94 & 7.78 \\
8 & 10.58 & 8.76 & 19.2 & 21.4 & 16.12 & 18.81 & 5.05 & 7.83 \\
9 & 3.58 & 8.58 & 17.7 & 53.1 & 10.18 & 21.19 & 2.25 & 5.62 \\
10 & 3.12 & 9.79 & 9.1 & 30.8 & 3.28 & 20.3 & 2.85 & 7.16 \\
11 & 3.55 & 9.04 & 0 & 21.7 & 0.9 & 10.3 & 4.11 & 5.76 \\
12 & 5.43 & 10.78 & 0 & 9.1 & 0.3 & 10 & 6.99 & 9.69
\end{tabular}

Abbreviations: $\mathrm{CM}-\mathrm{Mad}=$ Castilla la Mancha and Madrid; $\quad$ Extremad $=$ Extremadura; Basque C. $=$ Basque Country answ $=$ answers; $\mathrm{B}=$ Before, $\mathrm{A}=$ After 
Table II: Calculation of the increase in correct answers after the educational campaign given by AESLEME, for Spain as a whole and in some regions.

Data for the whole of Spain:

$\begin{array}{lcll} & \text { Correct } & \text { Incorrect } & \text { Total } \\ \text { After } & 56,529 & 40,743 & 97,272 \\ \text { Before } & 55,005 & 52,226 & 97,272 \\ \text { Total } & 101,534 & 93,010 & 194,554\end{array}$

Chi-squared $=716$ p $<0.00001 ;$ OR : $1.61 ; C L 95: 1.53$ and 1.64

Global increase in correct answers: 61\% with CL95: 53\% and 64\%

\section{Andalusia:}

$\begin{array}{lcll} & \text { Correct } & \text { Incorrect } & \text { Total } \\ \text { After } & 7,499 & 1,813 & 9,312 \\ \text { Before } & 4,862 & 4,450 & 9,312 \\ \text { Total } & 12,361 & 6,263 & 18,624\end{array}$

Chi-squared $=672 \mathrm{p}<0.00001 ; \mathrm{OR}: 3.78 ; \mathrm{CL} 95: 3.54$ and 4.04

Global increase in correct answers: 278\% with CL95: 254\% and 304\%

$\begin{array}{lcll}\text { Aragon: } & & & \\ & \text { Correct } & \text { Incorrect } & \text { Total } \\ \text { After } & 3,475 & 1,745 & 5,220 \\ \text { Before } & 2,672 & 2,548 & 5,220 \\ \text { Total } & 6,047 & 4,393 & 10,440\end{array}$

Chi-squared $=255$ p $<0.00001 ;$ OR : 1.89; CL95: 1.75 and 2.05

Global increase in correct answers: 89\% with CL95: 75\% and 105\%

\section{Canary Islands:}

$\begin{array}{lrll} & \text { Correct } & \text { Incorrect } & \text { Total } \\ \text { After } & 15,900 & 14,343 & 30,240 \\ \text { Before } & 15,282 & 14,958 & 30,240 \\ \text { Total } & 31,182 & 29,298 & 60,480\end{array}$

Chi-squared $=25$ p $<0.00001 ; \quad$ OR : 1.08 CL95 :1.05 and 1.12

Global increase in correct answers: 8\% with CL95: 5 and $12 \%$

Legend: OR (odds ratio); CL95 : (95\% Confidence Limits) 
Table II. (cont.): Calculation of the increase in correct answers after the education on health given by AESLEME, for Spain as a whole and in some regions.

\section{Castilla la Mancha and Madrid:}

$\begin{array}{lcll} & \text { Correct } & \text { Incorrect } & \text { Total } \\ \text { After } & 1,956 & 420 & 2,376 \\ \text { Before } & 1,371 & 1,005 & 2,376 \\ \text { Total } & 3,327 & 1,425 & 4,752\end{array}$

Chi-squared $=343 \mathrm{p}<0.00001 ; \mathrm{OR}: 3.41 ; \mathrm{LC}_{95}: 2.99$ and 3.9 .

Global increase in correct answers: 241\% with CL95: 199 and 290\%

\section{Extremadura:}

$\begin{array}{lcll} & \text { Correct } & \text { Incorrect } & \text { Total } \\ \text { After } & 5,973 & 2,067 & 8,040 \\ \text { Before } & 4,510 & 3,530 & 8,040 \\ \text { Total } & 10,483 & 5,597 & 16,080\end{array}$

Chi squared $=586 \mathrm{p}<0.00001 ; \mathrm{OR}: 2.26$; LC95 :2.11 and 2.42

Global increase in correct answers: 126\% with CL95: 111 and 142\%

\section{Basque Country:}

$\begin{array}{lrll} & \text { Correct } & \text { Incorrect } & \text { Total } \\ \text { After } & 21,727 & 20,357 & 42,084 \\ \text { Before } & 16,312 & 25,772 & 42,084 \\ \text { Total } & 38,039 & 46,129 & 84,168\end{array}$

Chi-squared=1406 p<0,00001 ; OR : 1.68; LC95 : 1.64 and 1.73

Global increase in correct answers: $68 \%$ with CL95: 64 and 73\%

Legend: OR (odds ratio); CL95: (95\% Confidence Limits)

\section{Discussion}

As countries develop, traffic increases and work is concentrated in cities; this normally increases road use and thus road accidents, along with other problems, such as air pollution, noise pollution, changes in the health of people living in areas where there are many vehicles, etc. Numerous countries have adopted policies to reduce vehicle traffic by encouraging the use of public transport, restricting vehicles going through certain areas of cities, increasing taxes on fuel, etc., with varying degrees of success in reducing traffic and accidents.

Most countries have also implemented road safety campaigns. Different strategies have been used - from very coercive ones (using deterrents or fining offenders) to more liberal ones based on raising awareness so that people adapt precautionary principles to changing day-to-day traffic situations - instead of just surveillance and punishment; these are not always effective, and also lead to behaviour that tries to thwart the effect of the 
surveillance (radar detectors or using computer programmes to warn other drivers that the police are at a particular junction, etc.), while a tendency to travel without adopting proper prevention strategies, and with it the risk of traffic accidents, continues.

This is why it is imperative to teach road safety from an early age as it helps to prevent the creation of attitudes that can become part of the chain of events that lead to road accidents, either as active agents (drivers, and sometimes passengers who accompany the driver, or pedestrians who jaywalk or walk in inappropriate places), or as passive agents (usually passengers and pedestrians).Just as with efforts to reduce smoking, a sedentary lifestyle, obesity, hypertension, etc. ${ }^{13-17}$, a number of different campaigns to prevent road traffic accidents have been implemented by most countries using a variety of methods, intensity of application and duration. For example, the Centre for Road Safety in New South Wales has created campaigns, such as Towards Zero, Saving Lives on Country Roads, Ride to Live, etc.). In Spain, the DGT (Directorate-General for Traffic) has designed campaigns, such as The Glass Man, Top Holiday, Distractions, etc., but in AESLEME's campaigns a differential element has been introduced: knowledge is accompanied by testimonies and the view of someone who has suffered this kind of accident, which provides credibility and great conviction to everything that is said ${ }^{11,12,18}$. In addition, teaching methods have greatly improved since the first presentations given 30 years ago, and virtual reality together with enhanced audiovisual mediums etc. - allows for a better adaptation to different audiences.

The study was easy to conduct, but risky in its objectives:

-Easy, because each teenager was not given an identification number, which could be lost, changed, forgotten, etc., since they did not know which specific day the second part of the study was going to be conducted. This prevented an individual comparative study of the 'before/after' responses, but not a joint study (of the whole class), which also demonstrated the effect of the didactic presentation given.

-Risky, since, if the presentation had not left a sufficiently powerful memory, the 'before/after' result would have tended towards a 'null effect'. However, if the effect was positive after a month, it would be a sign of integration of this knowledge in adolescents, which could lead to behaviour modification towards greater road safety.

As can be seen by the statistics, this didactic approach has proven to be effective for acquiring knowledge in just 1/2 hours, in Spain as a whole and in the regions where the study was conducted - with similar multiple-choice tests taken before and then one month later. The results varied in their degree of effectiveness, as we have seen, but they always point in the same direction (consistency of the effect) despite being conducted by different people and in very different places; this proves that the method chosen is reliable and makes this average increase in knowledge of $61 \%$ very valuable (with confidence limits of 95\%: 53\%-64\%) compared with those who participated in the survey before starting the road safety education activity. These good results support the Protection Motivation Theory ${ }^{19}$, which focuses on risk perception through perceived severity and vulnerability.

Limitations of the study: the number of before/month-after answers of each of the schoolchildren has not been studied due to the design of the survey as it ensures anonymity. This also complicated the type of statistical studies that demonstrate the effect. However, despite only having this overall assessment (by school year, school, city and region), a huge effect was appreciated after one month, even without any further education, which is most likely due to the great emotional and educational impact contained in the presentation given by AESLEME's instructors.

As it depended on the willingness and facilities provided by each school for the instructors to return the following month and take the second survey, it was not conducted in every region in Spain. We therefore believe that there was no response bias in the schools that collaborated, yet the increase in knowledge was significant in all of them.

Finally, it is impossible to know if what has been examined by this paper will increase knowledge to provide road accident prevention, but there are studies ${ }^{20-27}$ that demonstrate a positive association between knowledge of traffic rules, better risk perception and 
future safer road behaviours, provided that the programmes are highly educational and adapted to the profile of the students. In addition, they should be complemented with excursions to safe, traffic-free streets accompanied by teachers and urban police officers in order to further cement the theory with practical classes ${ }^{27}$.

It must also be said that not all researchers 27,28 agree with this correlation between knowledge and preventive attitudes to reduce road accidents, since there are many other factors involved in this causal chain, such as the example and attitudes of parents and friends, which can antagonize (or synergize) preventive attitudes derived from any traffic accident prevention programme ${ }^{29-31}$.

However, we believe, as do other authors 20,32, that school environments are particularly conducive for laying the foundations for the acquisition of the correct attitudes for preventing traffic accidents. This is because they act on very large populations at a key moment of their lives, in which many of their attitudes to life are shaped; this is even more true if the educational programme includes a presentation as impactful as ours, the effects of which remain a month after being carried out.

\section{Conclusions}

- Road accidents are a social and economic drain on all countries, even the most developed ones, so constant and effective prevention measures must be implemented.

- Prevention measures can be of a dissuasive/coercive nature - although their effectiveness is limited - in line with different countries and the idiosyncrasies of their populations, but above all they should offer education on both individual and collective risk/prevention awareness.

- Every country has many programmes, and there are different ways of educating. In Spain, AESLEME has been carrying out this work for 30 years with children, youngsters, and adults.

- Increased knowledge on road safety was assessed in over 8,000 people one month after presentations offered by AESLEME's instructors, with the attainment of an average of $61 \%$ (confidence limits of $95 \%$ : $53 \%$ and $64 \%$ ), which is statistically important.

Author Contributions: Conceptualization, Mar Cogollos, Juan Angel García-Reneses and Rafael Herruzo.

Acknowledgments: To everyone who works, or has worked, at AESLEME over these 30 years, thank you for your dedication, professionalism, and real-life examples. Thank you to everyone who has contributed to lowering the number of fatalities and serious injuries in Spain these past three decades.

Conflicts of Interest: Mar Cogollos is AESLEME's Director, and this position is remunerated by this NGO. The two other signatories are members of its Board of Directors and are not remunerated by AESLEME.

\section{Highlights:}

- For 30 years, an innovative educational approach on health has been implemented.

- This method provides knowledge, values, and empathy that all help to internalize the education received.

- Schoolchildren were assessed a month after the presentation, and knowledge has increased significantly over the years.

- This increase is uneven across the various regions depending on the characteristics of the instructor, the students and the school, and ranges from less than $10 \%$ to almost $300 \%$.

- Despite offering education on safe and healthy behaviour for three decades, this study shows that there is still room for increased knowledge to grow. 


\section{Appendix A}
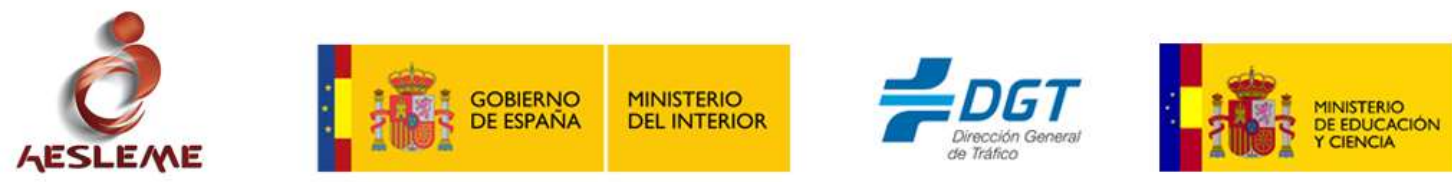

AESLEME is conducting an anonymous survey of its presentations. Your school, among many others, has been chosen to participate. Please answer all the questions honestly and without copying from anyone. Only choose one answer. Many thanks for your collaboration.

AGE:

MALE:

FEMALE:

NAME OF SCHOOL:

YEAR......

YOU ARE IN: CITY:

REGION:

DATE OF SURVEY:

1) In your opinion, what is the leading cause of death among people under the age of 19 ?
a) Drugs
b) Road accidents
c) Cancer
d) Sports accidents

2) Which of the following is the only consequence not involved in a spinal cord injury?
a) Loss of mobility
b) Loss of intelligence
c) Loss of sensation
d) Urinary problems

3) Which of the following regarding alcohol do you believe is true?
a) It slows your reflexes and slows your reaction time
b) It negatively affects how you judge of distance and speed
c) It reduces the ability to see the colour red (brake lights, traffic lights, etc.)
d) All of the above

4) Have you ever been in a car with friends who have drunk alcohol or taken some other kind of drug?
a) Never
b) At times
○ Alcohol
○ Drugs 
5) In your opinion, which of these is the biggest risk when driving?
a)
Speeding
b)
Distractions
c)
Alcohol and drugs
d)
Bad road conditions

6) In your opinion, which distraction leads to the most accidents?
a) Talking with a passenger
b) Fiddling/setting the GPS while driving
c) Looking for a track or radio station
d) Using a mobile phone

7) Using the seatbelts in the back of a car:
a) Is less important than using those in the front
b) Is just as important as using those in the front
c) Depends on how long the car journey is
d) Depends on whether the user wants to use it or not

8)

Which of the back seats in a car is the best for a child sitting in a government-approved safety seat?
a) Either of the side seats so that the back of the front seat can act as protection
b) The middle one with the 3-point seatbelt fastened correctly
c) The left-hand side one so that the front passenger can see the child
d) All of the back seats are equally safe if a seatbelt is used

9) The headrest in a car is in the correct position when the top edge is:
a) At the same height of the back of your neck
b) Lower than the back of your neck
c) At the height of the middle of your head
d) Higher than the middle of your head

10) Which kind of helmet is most recommendable: the flip-up type or the fixed, full-face type?
a) The fixed, full-face type because it absorbs the impact better if you have an accident
b) The flip-up type because on hot days the front opening keeps you cool
c) The flip-up type because the front opening means your airways can be accessed if you have an accident
d) Both helmets are equally good

11) If you witness an accident and no one is there to help, what is the first thing you should do?
a) Alert 112, Save, Protect (ASP)
b) Save, Alert 112, Protect (SAP)
c) Protect, Alert 112, Save (PAS)
d) Keep moving and don't stop 
12) If an arm is seriously bleeding, what should you do first to stop the haemorrhage?

a) Cover the bleeding wound with a clean cloth and not apply pressure

b) Make a tourniquet

c) Put pressure on the wound with an item of clothing

d) Just elevate the arm and it will stop bleeding

\section{References}

1. https://www.who.int/features/factfiles/roadsafety/es/

2. https://www.who.int/roadsafety/decade of action/en/

3. https://ec.europa.eu/commission/presscorner/detail/es/qanda 201004

4. https://ec.europa.eu/eurostat/tgm/table.do?tab=table\&init=1\&language $=$ en \&pcode $=$ sdg 11 40\&plugin $=1$

5. Racioppi, F.; Eriksson, L.; Tingvall, C.; Villaveces, A. Preventing road traffic injury.: A public health perspective for Europe. WHO Europe, 2004

6. https://www.epdata.es/datos/accidentes-trafico-datos-estadisticas/65/espana/106

7. Anuario Estadístico General 2019. Pub. Dirección General de Tráfico. Madrid 2019.

8. Peden M (Pub.). Proceedings of WHO Meeting to Develop a 5-year Strategy for Road Traffic Injury Prevention. WHO Geneva, 2001

9. Road traffic injury prevention: Training Manual. Unit 4. Implementing specific interventions to prevent road traffic injuries. WHO,Geneve 2005.

10. Goniewicz, K.; Goniewicz, M.; Pawłowski, W.; Fiedor, P. Road accident rates: strategies and programmes for improving road traffic safety. Eur J Trauma Emerg Surg. 2016, 42, 433-438.

11. Luciano, M.C.; Herruzo, J. Some relevant components of adherence behavior. J Behav Therap Experiment Psych, 1992, 23, 117-124

12. Bugaj, T.J.; Blohm, M.; Schmid, C.; Koehl, N.; Huber, J.; Huhn, D. et al. Peer-assisted learning (PAL): skills lab tutors' experiences and motivation. BMC Med Educ 2019, 19, 353 -https://doi.org/10.1186/s12909019-1760-2

13. Clevelanda, L.P.; Sewarda, M.W.; Simona, D.; Rifas-Shimana, S.L.; Lewisb, C.H.; Bennett-Rizzoc, C.; Halperind, F. ; McManuse, K.D.; Blocka, J.P. BW Healthy Weight Pilot Study: A randomized controlled trial to improve weight-loss maintenance using deposit contracts in the workplace, Prevent Med Reports. 2020, 17, 101061. https://doi.org/10.1016/i.pmedr.2020.101061

14. Gebauera, S.; Schootmanb, M.; Xianb, H.; Xaveriusb, P. Neighborhood built and social environment and meeting physical activity recommendations among mid to older adults with joint pain. Prevent Med Reports. 2020, 18, 101063. https://doi.org/10.1016/j.pmedr.2020.101063

15. Kinzie, M.B. Instructional design strategies for health behavior change. Patient Education and Counseling. 2005, 56, 3-15. 
16. Freedman, A.M.; Echt, K.V.; Cooper, H.L.F . Better Learning Through Instructional Science: A Health Literacy Case Study in "How to Teach So Learners Can Learn". Health Promot. Pract. 2012 ,13, 648-56

17. Agarwal, P.K.; Roediger, H.L. Lessons for learning: How cognitive psychology informs classroom practice. Phi Delta Kappan. 2018,100, 8-12

18. Pagès-Puigdemont, N.; Valverde-Merino, M.I. Medication Adherence: Modifiers and Improvement Strategies. Ars Pharm. 2018, 59, 251-258.

19. Roger, R.M. A protection motivation theory of fear appeals and attitude change. J Psychol. 1975, 91, 93114

20. Alonso, F.; Esteban, C. ; Useche, S.; Colomer, N. Effect of Road Safety Education on Road Risky Behaviours of Spanish Children and Adolescents: Findings from a National Study. Int. J. Environ. Res. Public Health 2018, 15, 2828. doi:10.3390/ijerph15122828

21. Dong, X.; Peek-Asa, C; Yang, J; Wang, S.; Chen, X; Chi, G.; Ramirez, M. The association of road safety knowledge and risk behaviour with paediatric road traffic injury in Guangzhou, China. Inj. Prev. 2011, 17, 15-20.

22. Cuenen, A.; Brijs, K.; Brijs, T.;Van Vlierden, K.; Daniels, S.; Wets, G. Effect evaluation of a road safety education program based on victim testimonials in high schools in Belgium. Acc. Anal. Prev. 2016, 94, 18-27.

23. Trifunovic, A.; Pesic, D; Cicevic, S.; Antic, B. The importance of spatial orientation and knowledge of traffic signs for children's traffic safety. Accid. Anal. Prev. 2017, 102, 81-92.

24. Jafarpour, S.; Rahimi-Movaghar, V. Determinants of risky driving behaviour: A narrative review. Med. J. Islam. Repub. Iran. 2014, 28, 142.

25. Hatfield, J.; Fernandes, R. The role of risk-propensity in the risky driving of young drivers. Accid. Anal. Prev. 2009, 41, 25-35. A

26. Guggenheim, N.; Taubman-Ben-Ari, O. Safe driving climate among friends (SDCaF): A new scale. Accid. Anal. Prev. 2018, 110, 78-85.

27. Alonso, F.; Esteban, C.; Useche, S.; Manso, V. Analysis of the State and development of road safety education in Spanish Higher Education Institutions. High. Educ. Res. 2016, 1, 10-18.

28. Zeedyk, M.S.; Wallace, L.; Carcary, B.; Jones, K.; Larter, K. Children and road safety: Increasing knowledge does not improve behaviour. Br. J. Educ. Psychol. 2001, 71, 573-594.

29. Taubman-Ben-Ari, O.; Musicant, O.; Lotan, T.; Farah, H. The contribution of parents' driving behaviour, family climate for road safety, and parent-targeted intervention to young male driving behaviour. Accid Anal. Prev. 2014, 72, 296-301.

30. Mehdizadeh, M.; Nordfjaern, T.; Mamdoohi, A.R.; Mohaymany, A.S. The role of parental risk judgements, transport safety attitudes, transport priorities and accident experiences on pupils' walking to school. Accid Anal. Prev. 2017, 102, 60-71.

31. Ducheyne, F.; De Bourdeauhuij, I.; Lenoir, M.; Cardon, G. Effects of a cycle training course on children's cycling skills and levels of cycling to school. Accid. Anal. Prev. 2014, 67, 49-60.

32. Assailly, J.P. Road safety education: What works? Patient Educ. Couns. 2017, 100, S24-S29. 